\title{
An Introduction to Current Trends in Meat Microbiology and Hygiene
}

\author{
Sophia Johler ${ }^{1}$. Claudia Guldimann ${ }^{2}$
}

Accepted: 15 July 2021

(c) The Author(s) 2021

\begin{abstract}
Purpose of Review This editorial review aims to provide readers with an introduction to the Current Clinical Microbiology Report Special Issue "Meat Microbiology and Hygiene." It will provide an overview of overarching trends and developments in this field, introduce the articles presented in this Special Issue, and attempt to offer a glimpse into the future of meat microbiology and hygiene.

Recent Findings Meat production has been subjected to transformative changes within the last decade, and the focus of assuring meat safety has shifted to account for changing consumer demands as well as new microbial risks such as strains carrying antimicrobial resistance determinants.

Summary Assuring that meat products meet high safety standards remains crucial to consumers worldwide. New risk-based meat safety assurance systems leveraging latest technological advances are needed to protect consumers and promote public health.
\end{abstract}

Keywords Meat safety assurance systems $\cdot$ Antimicrobial resistance $\cdot$ Surface treatment $\cdot$ Game meat $\cdot$ Interventions

\section{Introduction}

The field of food safety has radically changed over the past two decades. The application of next-generation sequencing to outbreak detection now allows for the detection of much smaller outbreaks. On the other hand, increasingly globalized food supply chains lead to much more dispersed outbreaks and pose new and sometimes impossible challenges in tracing foodborne pathogens to their sources. Changing consumer habits increase the demand for minimally processed foods with new risk profiles, and the emerging middle class in many formerly poor countries causes an increased demand for meat. Accordingly, the global demand for meat has quadrupled over the past 50 years, and a clear trend towards convergence of meat consumption habits worldwide was reported [1].

This article is part of the Topical Collection on Bacteriology

Claudia Guldimann

c.guldimann@1mu.de

1 Chair for Food Safety and Analytics, University of Zurich, Zurich, Switzerland

2 Institute for Food Safety and Analytics, Veterinary Faculty, Ludwig-Maximilians-Universität Munich, Munich, Germany
However, meat mass production has major environmental and ethical implications that are raising concerns with consumers, a trend that may gain momentum with the resurgence of the environmental movement. The search for alternative protein sources has raised interest in insect-based products, which would require new approaches to assure control of parasitical, microbial, and chemical hazards related to insect consumption [2]. Also, recent advances in in vitro meat technologies demonstrated that biofabrication of meat is possible, evoking the vision of disease-free meat and a subsequent reduction of foodborne illness [3, 4].

Even in conventional meat production, consumer perceptions and demands may act as major drivers for change. While meat consumption has traditionally been associated with physical strength and vitality, the mass media discourse on meat-related health and disease has become highly controversial [5]. Consumer trust in Europe has been eroded by reports on the carcinogenicity of red and processed meat [6] as well as food scandals such as the dioxin scandal in 2011 or the horse meat scandal in 2013, which have impacted consumer choices [7]. It has been suggested that meat safety and authenticity can only be guaranteed by extensive monitoring [8].

Highest microbiological and hygienic quality standards for meat products are crucial to assure consumer health. 
The traditional meat inspection system developed in the nineteenth century relied heavily on visual inspection, palpation, and incisions and has been an effective tool in protecting consumers from the most relevant meat-borne zoonoses at that time such as brucellosis, tuberculosis, and cysticercosis [9]. However, since then, the microbiological and hygienic challenges have changed substantially, with the main zoonotic agents reported today being Campylobacter spp., Salmonella enterica, pathogenic Escherichia coli, and Yersinia enterocolitica [10]. As traditional meat inspection is not effective in reducing the risk related to these organisms and may even increase the risk of, e.g., carcass cross-contamination, new risk-based meat safety assurance systems are required [9]. The currently ongoing implementation of a risk-based meat safety assurance system in Europe is a disruptive innovation process and will thus likely face opposition from various stakeholders including meat inspectors. Building a system flexible enough to react to changing requirements will be crucial to avoid that today's risk-based meat safety assurance systems will rapidly become obsolete in case of emerging new pathogens.

To meet the demand, animal production, for instance in the poultry sector, is becoming highly automated. These trends contribute to changes in ecology and technology that can lead to the rise of emerging foodborne pathogens by creating new connections of habitats with food, or by enabling the occurrence of established pathogens in new foods. Automation and use of robotics increase in the primary and secondary processing of meat and have also brought about massive changes and interesting new concepts in the last years, especially in the poultry sector. Automated plants using stunning and slaughtering robots (Marel Meat, Boxmeer, The Netherlands; SFK Meat Systems A/S, Kolding, Denmark) allow for high-throughput, which creates use cases for artificial intelligence solutions in meat safety. Automation and online monitoring can be advanced by sensor technology including multispectral and hyperspectral imaging as well as Fourier-transform infrared spectroscopy [11]. These techniques can be employed to detect bone fragments and skin tumors, loads of bacterial pathogens, and chemical contaminants $[11,12]$. Also, it has been postulated that the use of hyperspectral imaging techniques in meat safety could be combined with other technologies for maximum effect, e.g., machine vision to track and inspect broilers in an automated fashion during the breeding process [13]. In the meat factory cell automation concept, work is organized in cell stations instead of lines, some elements of slaughter and cutting are merged, and the carcass is disassembled from the outside [14]. This would allow for easier application of novel diagnostic tools such as electromagnetic and imaging tools.

In addition to these trends that will shape the future of the meat industry, antimicrobial resistance, new methods of surface treatments, and the safety of more niche products like game meat have seen recent developments. For this special issue of Current Clinical Microbiology Reports, we collected current trends in meat microbiology and hygiene which are briefly introduced in the following paragraphs.

\section{Antimicrobial Resistance}

The rapid global emergence of antimicrobial resistance is a key challenge to public health worldwide. In 2015, antimicrobial resistance led to 33,000 human deaths and 874,541 disability-adjusted life years in the EU/EEA alone [15]. There is overwhelming evidence that food plays a role in the transmission of antimicrobial resistance via bacterial commensals and pathogens, based on the selection of antimicrobial resistance due to antimicrobial treatment of foodproducing animals [16]. Antimicrobials have been globally used in veterinary medicine for decades for prophylactic, metaphylactic, and therapeutic reasons, as well as in the form of antimicrobial growth promoters [17]. Following the ban on antimicrobial growth promoters in food-producing animals, the EU also committed to the goal of a $50 \%$ reduction in the sales of antimicrobial agents by 2030 for farmed animals as part of the Farm to Fork Strategy and European Green Deal.

In the face of a looming post-antibiotic era, there is an urgent need for improved monitoring and prevention strategies as well as new therapeutic targets [18]. In their review "Livestock-associated MRSA-current situation and impact from a veterinary public health perspective" (Fetsch et al., 2021), Fetsch and coworkers provide an overview of the occurrence and characteristics of livestock-associated methicillin-resistant Staphylococcus aureus (LA-MRSA). They lay out current initiatives and strategies for reporting, prevention, and control and highlight newest findings in the ongoing controversial discussion of the potential role of MRSA as a foodborne pathogen. Contamination levels of raw meat can be substantial, and cross-contamination during food preparation and consumption of undercooked meat were proposed to play a role in LA-MRSA dissemination, prompting EFSA to reinforce MRSA monitoring in foods and food-producing animals [19]. Whole-genome sequencing could play a decisive role in enabling new insights into the transmission and spread of LA-MRSA, thus allowing for the developments of more effective control strategies [19].

\section{Decontamination of Meat Surfaces}

Decontamination technologies aiming to reduce bacterial load of, e.g., Campylobacter, on meat surfaces are becoming increasingly important and may be an important cornerstone of post-harvest intervention strategies maximizing food safety [20]. Still, many of these technologies may lead to sensory deviations or have not been legally approved yet. 
In their review "Physical methods for the decontamination of meat surfaces" (Albert et al., 2021), Albert and colleagues provide an overview on latest developments regarding alternative non-thermal physical surface treatment technologies. They present applied technologies such as high-pressure processing and irradiation as well as the most promising technological advances for future use such as cold plasma and pulsed light UV-C treatment. All technologies are assessed with regard to their efficiency for reduction of bacterial load, their capacity to preserve food quality, and acceptance by the consumer.

\section{Alternative Curing Methods}

Salt has been used in meat preservation for centuries, and curing of meat products is an important cornerstone in assuring product safety. However, consumers are increasingly aware of potential negative health effects of conventionally cured meat products, sparking a growing demand for organic or "naturally cured" meat products with no direct addition of nitrate or nitrite [21]. Alternative curing methods relying on nitrate-reducing starter cultures, plasma treatment, or the addition of vegetable-based ingredients high in nitrate, can result in products exhibiting characteristics that closely resemble conventionally cured meat. Still, the amount of nitrite present in the final product may be difficult to steer and potential negative health effects due to consumption of nitrite remain unchanged [21]. In their review "4" (Siekmann et al., 2021), Siekmann and colleagues provide an overview of the wide range of "natural curing" technologies that have been proposed as a replacement for conventional curing, with a particular focus on addition of plants and their extracts as well as plasma treatment for nitrate generation. They also discuss microbiological implications and the efficacy of the hurdle principle to assure consumer safety.

\section{Meat Safety of Game Meat}

There is much less data on the microbial safety of game than for conventionally slaughtered animals, and data collection is less harmonized [22].

Ensuring safe meat from wild game comes with a specific set of challenges. It is inherent in the hunting process that hygiene levels, time to evisceration, and time to cooling do not always adhere to the same strict controls and standards as for animals that are processed in slaughterhouses, leading to an elevated threat of contamination [23, 24] with chemical hazards (e.g., lead from ammunition [25]), as well as parasites, bacteria, or viruses. In their review "Wild game meat - a microbiological safety and hygiene challenge?," Gomes-Neves et al. focus on bacterial and viral safety of wild game. They review recent publications on the safety of game meat, in particular wild boar, deer and other ruminants, lagomorphs, and prey birds. They identify a large gap between the microbial quality of farmed meat in comparison with game and advise the inclusion of game meat in surveillance and monitoring programs within the EU. It also seems advisable to increase research efforts into the microbial safety of game birds and to monitor AMR in wild animal populations more closely.

\section{Pre-harvest Food Safety on Broiler Farms}

In their systematic review, Pessoa et al. summarize current trends in pre-harvest food safety and discuss their effectiveness at either reducing the prevalence of flocks that are positive for a specific pathogen (e.g., biosecurity measures) or reducing the pathogen load in individual animals that came from colonized flocks (e.g., measures to increase host resistance). Most studies focused on Campylobacter and Salmonella as the main hazards. Biosecurity interventions were the most suitable approach to reduce Campylobacter [26, 27], while competitive exclusion or bacteriophages were more successful at managing Salmonella [28].

The authors identify a pronounced lack of new immunization strategies for foodborne pathogens since the successful implementation of the Salmonella vaccination program in broilers starting 2008 in the EU.

\section{Campylobacter spp. in Broiler Meat}

Given the high prevalence of Campylobacter in poultry meat, Kittler et al. discuss methods to mitigate Campylobacter along the poultry production chain in more detail in their review "A One Health perspective on a multi-hurdle approach to combat Campylobacter spp. in broiler meat." Infections with Campylobacter jejuni and coli rank at the top of the most commonly reported foodborne illnesses worldwide, with undercooked poultry and milk as the main source for human infections. Their review gives a risk assessment for the spread of Campylobacter along the food production chain. They emphasize the importance of a hurdle principle and summarize recent findings for strategies ranging from efficient detection methods, access control for personnel and equipment between different flocks, chemical and biological disinfection of feed, water, and facilities, to an update on vaccination programs for broiler flocks. Not surprisingly, defeathering and evisceration are still the key risk factors for contamination of the final product during slaughter. The control of viable but non-culturable (VBNC) cells forming after environmental stress might be leveraged to increase food safety further, even though their significance is discussed controversially. 


\section{Conclusion}

In order to adequately address emerging and current challenges in food safety, there is a need for multidisciplinary research along the food chain from farm to fork to address emerging food safety risks in a One Health approach. An example of the successful implementation of this approach is the collaboration of experts in animal husbandry, pharmacology, molecular biology, and immunology who addressed the root cause of human infections with Salmonella enterica by developing a vaccine program in poultry, thereby decreasing the overall number of human cases by over $30 \%$ in the EU within a few years [29].

Collaboration of experts across different fields in a One Health approach can contribute to the production of economically sound, safe, and healthy food animals. It can help to address challenges like the propagation of antimicrobialresistant bacteria along the food chain or to prevent food fraud. Interdisciplinary teams are able to design data-driven prevention programs, realistic models of microbial spread, or new analytical methods. They can push research into basic concepts of the interaction of viral, bacterial, and parasitic foodborne pathogens with the environment and host. A fundamental understanding of these processes will ultimately lead to a better understanding of the pathophysiology of foodborne diseases and their resistance against antimicrobials and disinfectants, and may be used to guide better practices in animal and food production, serve regulatory agencies to implement science-based regulations, and contribute to better overall food safety.

Funding Open Access funding enabled and organized by Projekt DEAL.

Open Access This article is licensed under a Creative Commons Attribution 4.0 International License, which permits use, sharing, adaptation, distribution and reproduction in any medium or format, as long as you give appropriate credit to the original author(s) and the source, provide a link to the Creative Commons licence, and indicate if changes were made. The images or other third party material in this article are included in the article's Creative Commons licence, unless indicated otherwise in a credit line to the material. If material is not included in the article's Creative Commons licence and your intended use is not permitted by statutory regulation or exceeds the permitted use, you will need to obtain permission directly from the copyright holder. To view a copy of this licence, visit http://creativecommons.org/licenses/by/4.0/.

\section{References}

1. Allievi F, Vinnari M, Luukkanen J. Meat consumption and production - analysis of efficiency, sufficiency and consistency of global trends. J Clean Prod. 2015;92:142-51. Available from: https://doi.org/10.1016/j.jclepro.2014.12.075
2. Belluco S, Losasso C, Maggioletti M, Alonzi CC, Paoletti MG, Ricci A. Edible insects in a food safety and nutritional perspective: a critical review. Compr Rev Food Sci Food Saf. 2013;12:296313. https://doi.org/10.1111/1541-4337.12014.

3. Bhat ZF, Kumar S, Fayaz H. In vitro meat production: challenges and benefits over conventional meat production. J Integr Agric. 2015;14:241-8. Available from: https://doi.org/10.1016/S20953119(14)60887-X

4. Bhat ZF, Kumar S, Bhat HF. In vitro meat: a future animal-free harvest. Crit Rev Food Sci Nutr. 2017;57:782-9. https://doi.org/ 10.1080/10408398.2014.924899.

5. Leroy F, Brengman M, Ryckbosch W, Scholliers P. Meat in the post-truth era: mass media discourses on health and disease in the attention economy. Appetite. 2018;125:345-55. Available from: https://doi.org/10.1016/j.appet.2018.02.028

6. Bouvard V, Loomis D, Guyton KZ, Grosse Y, Ghissassi F El, Benbrahim-Tallaa L, et al. Carcinogenicity of consumption of red and processed meat. Lancet Oncol. 2015;16:1599-600. Available from: https://doi.org/10.1016/S1470-2045(15)00444-1

7. Rieger J, Kuhlgatz C, Anders S. Food scandals, media attention and habit persistence among desensitised meat consumers. Food Policy. 2016;64:82-92. Available from: https://doi.org/10.1016/j. foodpol.2016.09.005

8. Premanandh J. Horse meat scandal - a wake-up call for regulatory authorities. Food Control. 2013;34:568-9. Available from: https:// doi.org/10.1016/j.foodcont.2013.05.033

9. Blagojevic B, Nesbakken T, Alvseike O, Vågsholm I, Antic D, Johler S, et al. Drivers, opportunities, and challenges of the European risk-based meat safety assurance system. Food Control. 2021;124:107870. Available from: https://doi.org/10.1016/j.foodc ont.2021.107870

10. The European Union One Health 2018 Zoonoses Report. EFSA J. 2019;17. Available from: https://doi.org/10.2903/j.efsa.2019.5926

11. Piloli. Chapter 5: Sensors and biosensors for meat safety: recent advances in nanotechnology integration. In: Meat Processing, 2nd Edition.

12. Wang W, Zhang H, Yan L, Zhou H, Chen C, Xu B, et al. A rapid and non-destructive approach to identify bone fragments embedded in lean pork slices based on multispectral imaging and chemometrics. Infrared Phys Technol. 2021;113:103575. Available from: https://doi.org/10.1016/j.infrared.2020.103575

13. Fu X, Chen J. A review of hyperspectral imaging for chicken meat safety and quality evaluation: application, hardware, and software. Compr Rev Food Sci Food Saf. 2019;18:535-47. https://doi.org/ 10.1111/1541-4337.12428.

14. Alvseike O, Prieto M, Torkveen K, Ruud C, Nesbakken T. Meat inspection and hygiene in a meat factory cell - an alternative concept. Food Control. 2018;90:32-9. Available from: https://doi.org/ 10.1016/j.foodcont.2018.02.014

15. Cassini A, Högberg LD, Plachouras D, Quattrocchi A, Hoxha A, Simonsen GS, et al. Attributable deaths and disability-adjusted life-years caused by infections with antibiotic-resistant bacteria in the EU and the European Economic Area in 2015: a populationlevel modelling analysis. Lancet Infect Dis. 2019;19:56-66. Available from: https://doi.org/10.1016/S1473-3099(18)30605-4

16. WHO. WHO guidelines on use of medically important antimicrobials in food-producing animals. 2017. Available from: https://www.who.int/foodsafety/publications/cia_guidelines/en/. Accessed 19 May 2021

17. Schwarz S, Kehrenberg C, Walsh TR. Use of antimicrobial agents in veterinary medicine and food animal production. Int J Antimicrob Agents. 2001;17:431-7. Available from: https://doi.org/10. 1016/S0924-8579(01)00297-7

18. Johler S. A glimpse into the future - new therapeutic targets could transform the way we treat staphylococcal infections. Virulence. 
2017;8:1508-10. https://doi.org/10.1080/21505594.2017.13931 38.

19. Aerts M, Battisti A, Hendriksen R, Kempf I, Teale C, Tenhagen $\mathrm{B}$, et al. Technical specifications on harmonised monitoring of antimicrobial resistance in zoonotic and indicator bacteria from food-producing animals and food. EFSA J. 2019;17. Available from: https://doi.org/10.2903/j.efsa.2019.5709

20. EFSA Panel on Biological Hazards (BIOHAZ). Scientific opinion on Campylobacter in broiler meat production: control options and performance objectives and/or targets at different stages of the food chain. EFSA J. 2011;9:2105.

21. Sebranek JG, Bacus JN. Cured meat products without direct addition of nitrate or nitrite: what are the issues? Meat Sci. 2007;77:136-47. Available from: https://doi.org/10.1016/j.meats ci.2007.03.025

22. Consortium Enet, Vicente J, Plhal R, Blanco-Aguiar JA, Sange M, Podgórski T, et al. Analysis of hunting statistics collection frameworks for wild boar across Europe and proposals for improving the harmonisation of data collection. EFSA Support Publ. 2018;15. Available from: https://doi.org/10.2903/sp.efsa.2018. EN-1523

23. Gill CO. Microbiological conditions of meats from large game animals and birds. Meat Sci. 2007;77:149-60. Available from: https://doi.org/10.1016/j.meatsci.2007.03.007

24. Paulsen P, Smulders FJM, Hilbert F. Salmonella in meat from hunted game: a Central European perspective. Food Res Int. 2012;45:609-16. Available from: https://doi.org/10.1016/j.foodr es.2011.06.055
25. Thomas VG, Pain DJ, Kanstrup N, Green RE. Setting maximum levels for lead in game meat in EC regulations: an adjunct to replacement of lead ammunition. Ambio. 2020;49:2026-37. https://doi.org/10.1007/s13280-020-01336-6.

26. Battersby T, Whyte $\mathrm{P}$, Bolton D. Protecting broilers against Campylobacter infection by preventing direct contact between farm staff and broilers. Food Control. 2016;69:346-51. Available from: https://doi.org/10.1016/j.foodcont.2016.04.053

27. Soro AB, Whyte P, Bolton DJ, Tiwari BK. Strategies and novel technologies to control Campylobacter in the poultry chain: a review. Compr Rev Food Sci Food Saf. 2020;19:1353-77. https:// doi.org/10.1111/1541-4337.12544.

28. Sevilla-Navarro S, Catalá-Gregori P, García C, Cortés V, Marin C. Salmonella Infantis and Salmonella Enteritidis specific bacteriophages isolated form poultry faeces as a complementary tool for cleaning and disinfection against Salmonella. Comp Immunol Microbiol Infect Dis. 2020;68:101405. Available from: https://doi. org/10.1016/j.cimid.2019.101405

29. Antunes P, Mourão J, Campos J, Peixe L. Salmonellosis: the role of poultry meat. Clin Microbiol Infect. 2016;22:110-21. https:// doi.org/10.1016/j.cmi.2015.12.004

Publisher's Note Springer Nature remains neutral with regard to jurisdictional claims in published maps and institutional affiliations. 